\title{
White blood cell count to mean platelet volume ratio as a novel non-invasive marker predicting long-term outcomes in patients with non-ST elevation acute coronary syndrome
}

\author{
Mohammad Reza Dehghani ${ }^{1}$, Yousef Rezaei ${ }^{2}$, Leila Taghipour-Sani ${ }^{1}$ \\ ${ }^{1}$ Department of Cardiology, Seyyed-al-Shohada Heart Center, \\ Urmia University of Medical Sciences, Urmia, Iran \\ ${ }^{2}$ Seyyed-al-Shohada Heart Center, Urmia University of Medical Sciences, Urmia, Iran
}

\begin{abstract}
Background: Total white blood cell (WBC) count and mean platelet volume have previously been shown to predict outcomes in acute coronary syndrome (ACS) patients. In this prospective study, we sought to determine the prognostic value of baseline WBC count to mean platelet volume ratio (WMR) in patients with non-ST elevation acute coronary syndrome (NSTE-ACS). Methods: A total of 490 patients with NSTE-ACS were prospectively enrolled. The relationship between baseline WMR and major adverse cardiovascular events (MACE) incidence was assessed during a mean follow-up of $330.8 \pm 38$ days.

Results: The patients' mean age was $60.4 \pm 12.9$ year, $59 \%$ of them were male. The patients were categorized into two groups based on WMR values, high-and low-WMR groups $(<755$ $v s . \geq 755)$. The incidence of MACE was significantly higher in high-WMR compared with that of low-WMR group (22.4\% vs. 10.7\%, p < 0.001). Total WBC counts (median 7.9 vs. $6.9 \times 10^{3} / \mu L, p=0.004$ ), neutrophil count (median 4.6 vs. $4.2 \times 10^{3} / \mu L, p=0.021$ ), and WMR (median 863.2 vs. 731.5, $p=0.001$ ) were significantly higher in the MACE-positive than MACE-negative group. The high-WMR was found to be significantly associated with the $M A C E$-free survival rate $(p<0.001)$. In an adjusted cox regression model, the elevated WMR was independently predicted the incidence of MACE (hazard ratio 2.419, 95\% CI 1.515-3.862, $p<0.001$ ).
\end{abstract}

Conclusions: The elevated baseline WMR independently predicted the MACE incidence in patients with NSTE-ACS during long-term follow-up. (Cardiol J 2015; 22, 4: 437-445)

Key words: white blood cell to mean platelet volume ratio, non-ST elevation acute coronary syndrome, major adverse cardiovascular events

\section{Introduction}

Atherosclerosis has been postulated to be an inflammatory disease [1]. Given previous studies, acute coronary events are not only attributable to the progressive narrowing of coronary artery lumen, but also to other pathophysiological factors involved in the development of such events. Atherosclerotic plaques ruptured and contribute to thrombus formation by inflammatory mechanisms,

Address for correspondence: Yousef Rezaei, MD, Seyyed-al-Shohada Heart Center, Urmia University of Medical Sciences, Urmia 5718749441, Iran, tel: +98-912-623-1864, fax: +98-441-237-5907, e-mail: yousefrezaei1986@gmail.com 
through which it can lead to the development of acute coronary syndrome (ACS) [2].

Leukocytes have been shown to be involved in the inflammatory processes, which have potential roles in the development of cardiovascular events [3]. T-cells and macrophages located in the lipid core of an atherosclerotic plaque are activated after endothelial injury, and those promote the thrombus formation as a result of producing cytokines and procoagulants. Therefore, all these processes enhance the thrombogenicity and the development of ACS [2]. Besides leukocytes, platelets have been reported to participate in the development of acute coronary events through inflammatory pathways [4]. Activated and inactivated platelets promote platelet-leukocytes adhesion, including adhesion molecules and cytokines, which result in the progression of atherogenesis [5]. The interaction between platelets and leukocytes can be attributed to the enhancement of leukocyte recruiting at the site of plaque rupture, and this may be of great importance in the development of ACS or its prognosis [5]. The interactions between these cells may be a pathogenic mechanism involved in the occlusion of coronary arteries during an ACS event [6].

The mean platelet volume, a platelet activation marker [7], and leukocyte differentials [8-10] have been reported to be associated with cardiovascular morbidity and mortality. The components of complete blood count test have been increasingly used in cardiovascular setting and correlated with clinical outcomes. Hence, in this prospective study, we sought to determine whether the baseline white blood cell (WBC) count to mean platelet volume ratio (WMR) can predict the long-term outcomes in patients with non-ST elevation ACS (NSTE-ACS).

\section{Methods}

\section{Study design and population}

The present study was conducted in the Seyyed-al-Shohada Heart Center of Urmia University of Medical Sciences, Urmia, West-Azerbaijan province, Iran, to investigate the prognostic role of complete blood count components in the setting of ACS. Therefore, 862 consecutive patients who had been admitted to the Emergency Department with chief complaint of new onset chest discomfort were assessed from August 2012 to March 2013. A total of 490 patients with a diagnosis of NSTE-ACS were enrolled. This study was approved by both the local Ethics Committee of Urmia University of Medical Sciences and our institutional Review
Board; and informed consents were obtained from all the participants.

All patients complaining of chest discomfort were evaluated using full examination, cardiac ischemia markers (creatine kinase MB isoenzyme [CK-MB] and troponin I), routine biochemical markers, and a 12-lead electrocardiogram (ECG). Unstable angina was defined as ischemic changes in ECG without increasing in cardiac enzymes. Non-ST segment elevation myocardial infarction (NSTEMI) was defined as patients without ST-segment elevation in their ECG but with an increase in the cardiac ischemia markers. The diagnosis of ST-segment elevation myocardial infarction (STEMI) was regarded as patients with typical ischemic chest pain lasting more than 20 min associated with one of the features, including at least $1 \mathrm{~mm}$ ST-segment elevation, a new $\mathrm{Q}$ wave, a new onset left bundle branch block in $\geq 2$ contiguous leads, and/or the elevation of cardiac markers at least 2 -fold of the maximum normal values. A non-ACS patient was considered a case whose chest pain was atypical without ischemic changes in ECG and/or an increase in cardiac markers. Exclusion criteria included non-ACS patients, STEMI, cancer history, inflammatory diseases, autoimmune diseases, infectious diseases, and being immunosuppressed. Additionally, due to small numbers of NSTE-ACS patients undergoing revascularization at the time of study conduction, we excluded such cases. To identify the incidence of major adverse cardiovascular events (MACE), all the patients were followed up to December 2013. The patients who had unstable angina were given anticoagulants (aspirin plus clopidogrel), beta-blocker, angiotensin converting enzyme inhibitors, nitrate, and statin. The NSTEMI patients were also treated as unstable angina ones. Furthermore, none of the patients underwent revascularization therapy. All blood samples were provided at admission and analyzed within 30 min of sampling by an automated blood cell counter (Sysmex, Kobe, Japan).

\section{Clinical outcomes}

All patients were followed for a mean of $330.8 \pm$ \pm 38 days. The measured clinical outcomes were as follows: (1) rehospitalization due to unstable angina; (2) any kind of cardiac arrhythmias required invasive therapies, including long-term consumption of anti-arrhythmic drugs and/or implementing implantable cardioverter defibrillator, which were continued up to end of follow-up time; (3) non-fatal MI; (4) and cardiac death. These endpoints were considered a composite MACE $(n=81)$. 


\section{Statistical analysis}

WBC count, mean platelet volume, and WMR levels were divided into two groups according to their median values as follows: (1) WBC count $<7.1 \times 10^{3} / \mu \mathrm{L}$ or $\geq 7.1 \times 10^{3} / \mu \mathrm{L}$; (2) mean platelet volume $<9.5 \mathrm{fL}$ or $\geq 9.5 \mathrm{fL}$; and (3) WMR $<755$ or $\geq 755$. All continuous variables were reported as either median ( $25^{\text {th }}$ and $75^{\text {th }}$ percentiles) or mean \pm standard deviation and those were analyzed using the Mann-Whitney U test or t-test, respectively. Categorical variables were reported as number (percentage) and compared by the $\chi^{2}$ test. The receiver operating characteristics (ROC) curve analysis was conducted for the detection of diagnostic accuracy of biochemical markers. The Kaplan-Meier analysis was used to detect the MACE-free survival rate, and log-rank test was applied to calculate its significance. In addition, a multivariate Cox regression analysis, backward stepwise model, was used to identify the independent predictors of composite MACE at follow-up period. In this model, all baseline characteristics, drug histories, conventional cardiovascular risk factors, biomarkers, the status of diagnosis consisting of unstable angina or NSTEMI, and having multi-vessel disease were considered covariates, and MACE incidence was entered as a dependent variable. In the backward stepwise model, $p$ value $>0.1$ was applied for removing the covariates. The values of $\mathrm{WBC}$, mean platelet volume, and WMR were entered as categorical variables based on their medians, high- vs. low-value. Moreover, in an adjusted Cox regression model, all variables whose $\mathrm{p}$ values were less than 0.05 were entered into another model. All statistical analyses were performed using SPSS, version 18.0 (SPSS Inc., Chicago, IL, USA). A 2-tailed p value less than 0.05 was considered statistically significant.

\section{Results}

\section{Characteristics, clinical features, and biomarkers}

The patients' mean age was $60.4 \pm 12.9$ year, and no significant difference was observed between the high- and low-WMR groups ( $\mathrm{p}=0.052) ; 59 \%$ of the patients were male $(\mathrm{p}=0.069)$. Heart rate at presentation was significantly greater in the highcompared with that in low-WMR group (median of 80 vs. $78 \mathrm{bpm}, \mathrm{p}=0.021$ ). The frequency of patients who had NSTEMI was higher in the highWMR group than low-WMR group (9\% vs. $18.7 \%$, $\mathrm{p}=0.002$ ). The more proportion of patients in the low-WMR group had consumed beta-blockers, nitrates, and dual anti-platelet therapy in comparison with those in the high-WMR group (Table 1). Among laboratories, mean platelet volume was significantly lower in the high-WMR compared with that in low-WMR group (median of 9.3 vs. $9.8 \mathrm{fL}$, $\mathrm{p}<0.001$ ), in contrast, the WBC count was greater in high-WMR compared with that in low-WMR group (median of 8.8 vs. $6 \times 10^{3} / \mu \mathrm{L}, \mathrm{p}<0.001$ ). Other characteristics and laboratories were summarized in the Table 1.

When comparing study variables between groups, MACE-positive vs. MACE-negative groups, the frequency of hypertension was significantly higher in the MACE-positive compared with that in the MACE-negative group $(66.7 \%$ vs. $54.5 \%, \mathrm{p}=0.044)$. Amongst the biomarkers, WBC count (median of 7.9 vs. $6.9 \times 10^{3} / \mu \mathrm{L}, \mathrm{p}=0.004$ ), neutrophil count (median of 4.6 vs. $4.2 \times 10^{3} / \mu \mathrm{L}$, $\mathrm{p}=0.021$ ), and WMR (median of 863.2 vs. 731.5, $\mathrm{p}=0.001$ ) were significantly higher in the MACE-positive compared with those of MACE-negative group (Table 2).

In subgroup analysis, patients who were younger than 65 years, male, smoker, and diagnosed with NSTEMI, had higher WMR values compared with patients who were not (Fig. 1).

\section{Diagnostic and survival analysis}

According to the ROC curve analysis, the area under curve (AUC) for WMR was $0.595(95 \%$ confidence interval [CI] 0.519-0.671, $\mathrm{p}=0.018$ ), and it was found to be higher than those of CK-MB and troponin I tests (Fig. 2).

The Kaplan-Meier analysis showed that the WMR subgroups ( $<755$ vs. $\geq 755$ ) were significantly associated with the MACE-free survival rate (log-rank test $\mathrm{p}$ value $<0.001$; Fig. 3 ).

\section{Multivariate analysis}

Based on the last step of backward stepwise multivariate analysis, male sex (hazard ratio [HR] 2.689, 95\% CI 1.277-5.662, $\mathrm{p}=0.009)$, having hypertension (HR 3.780, 95\% CI 1.860-7.861, p < $<0.001$ ), and a previous use of nitrates (HR 1.954, 95\% CI 1.073-3.558, $\mathrm{p}=0.029$ ) were found to be the predictors of MACE. Moreover, CK-MB (HR $1.013,95 \%$ CI 1.001-1.025, $\mathrm{p}=0.038)$, platelet count (HR 1.005, 95\% CI 1.001-1.009, $\mathrm{p}=0.014$ ), and hematocrit (HR $0.906,95 \%$ CI $0.839-0.978$, $\mathrm{p}=0.012$ ) were associated with the incidence of MACE. Furthermore, the high WMR (HR 2.406, 95\% CI 1.257-4.607, $\mathrm{p}=0.008$ ) was found to be the strongest marker predicting MACE during follow-up (Table 3). In an adjusted model, entering 
Table 1. Baseline characteristics, laboratories, and long-term outcomes according to white blood cell count to mean platelet volume ratio (WMR).

\begin{tabular}{|c|c|c|c|c|}
\hline & $\begin{array}{c}\text { Total } \\
(n=490)\end{array}$ & $\begin{array}{l}\text { Low-WMR } \\
\qquad(\mathrm{n}=232)\end{array}$ & $\begin{array}{c}\text { High-WMR }^{\mathrm{a}} \\
(\mathrm{n}=254)\end{array}$ & $\mathbf{P}$ \\
\hline Age [years] & $60.4 \pm 12.9$ & $61.5 \pm 12$ & $59.3 \pm 13.7$ & 0.052 \\
\hline Male & $289(59 \%)$ & $134(54.9 \%)$ & $155(63 \%)$ & 0.069 \\
\hline Body mass index $\left[\mathrm{kg} / \mathrm{m}^{2}\right]$ & $27.7(24.6,30.8)$ & $27.7(24.6,30.1)$ & $27.7(24.7,31.5)$ & 0.593 \\
\hline Heart rate $[\mathrm{bpm}]$ & $80(75,85)$ & $78(72,83)$ & $80(74,90)$ & 0.021 \\
\hline Systolic BP [mm Hg] & $137(125,150)$ & $136(125,150)$ & $137(125,150)$ & 0.870 \\
\hline Diastolic BP [mm Hg] & $80(78,90)$ & $81.5(76,90)$ & $80(80,90)$ & 0.917 \\
\hline NYHA: & & & & 0.594 \\
\hline Class 1 & $122(24.9 \%)$ & $55(22.5 \%)$ & $67(27.2 \%)$ & \\
\hline Class 2 & $74(15.1 \%)$ & $36(14.8 \%)$ & $38(15.4 \%)$ & \\
\hline Class 3 & $265(54.1 \%)$ & $139(57 \%)$ & $126(51.2 \%)$ & \\
\hline Class 4 & $29(5.9 \%)$ & $14(5.7 \%)$ & $15(6.1 \%)$ & \\
\hline Diabetes mellitus & $145(29.6 \%)$ & $67(27.5 \%)$ & $78(31.7 \%)$ & 0.303 \\
\hline Hypertension & $277(56.5 \%)$ & $142(58.2 \%)$ & $135(54.9 \%)$ & 0.459 \\
\hline Dyslipidemia & $87(17.8 \%)$ & $40(16.4 \%)$ & $47(19.1 \%)$ & 0.432 \\
\hline Current smoking & $129(26.3 \%)$ & $55(22.5 \%)$ & $74(30.1 \%)$ & 0.058 \\
\hline Familial history & $142(29 \%)$ & $67(27.5 \%)$ & $75(30.5 \%)$ & 0.460 \\
\hline Diagnosis: & & & & 0.002 \\
\hline Non-ST elevation MI & $68(13.9 \%)$ & $22(9 \%)$ & $46(18.7 \%)$ & \\
\hline Unstable angina & $422(86.1 \%)$ & $222(91 \%)$ & $200(81.3 \%)$ & \\
\hline Multivessel disease ${ }^{b}$ & $124(25.3 \%)$ & $70(28.7 \%)$ & $54(22 \%)$ & 0.086 \\
\hline \multicolumn{5}{|l|}{ Drug histories: } \\
\hline Beta-blockers & $226(46.1 \%)$ & $130(53.3 \%)$ & $96(39 \%)$ & 0.002 \\
\hline ACE-I & $76(15.6 \%)$ & $41(16.9 \%)$ & $35(14.3 \%)$ & 0.442 \\
\hline Statins & $209(42.7 \%)$ & $107(43.9 \%)$ & $102(41.5 \%)$ & 0.593 \\
\hline Nitrates & $184(37.9 \%)$ & $104(56.5 \%)$ & $80(43.5 \%)$ & 0.025 \\
\hline Dual anti-platelet & $112(22.9 \%)$ & $65(26.6 \%)$ & $47(19.1 \%)$ & 0.047 \\
\hline \multicolumn{5}{|l|}{ Biochemical markers: } \\
\hline CK-MB [IU/L] & $25(20,33)$ & $24(19,31)$ & $27(20,36)$ & 0.003 \\
\hline Troponin I [ng/ $\mu \mathrm{L}]$ & $0.01(0.01,0.2)$ & $0.01(0.01,0.08)$ & $0.01(0.01,0.3)$ & 0.005 \\
\hline $\mathrm{HDL}[\mathrm{mg} / \mathrm{dL}]$ & $38(33,44)$ & $38(33,44)$ & $39(34,45)$ & 0.202 \\
\hline LDL [mg/dL] & $86(70,104)$ & $84(67,100)$ & $88(72,105)$ & 0.051 \\
\hline Blood urea nitrogen [mg/dL] & $17.5(14,22)$ & $17(14,21)$ & $18(14,23)$ & 0.158 \\
\hline Creatinine $[\mathrm{mg} / \mathrm{dL}]$ & $0.9(0.8,1.1)$ & $0.9(0.8,1.1)$ & $0.9(0.8,1.1)$ & 0.103 \\
\hline Blood sugar [mg/dL] & $107.5(93,142)$ & $103(89,134.5)$ & $110.5(95,146)$ & 0.041 \\
\hline White blood cell count $\left[\times 10^{3} / \mu \mathrm{L}\right]$ & $7.1(6,8.8)$ & $6(5.3,6.7)$ & $8.8(7.8,10)$ & $<0.001$ \\
\hline Neutrophil $\left[\times 10^{3} / \mu \mathrm{L}\right]$ & $4.3(3.4,5.6)$ & $3.5(3,4.2)$ & $5.4(4.3,7.6)$ & $<0.001$ \\
\hline Lymphocyte $\left[\times 10^{3} / \mu \mathrm{L}\right]$ & $2(1.5,2.6)$ & $1.8(1.5,2.3)$ & $2.4(1.7,2.9)$ & $<0.001$ \\
\hline Red blood cell count $\left[\times 10^{6} / \mu \mathrm{L}\right]$ & $473(440,506)$ & $470(433.5,499.5)$ & $478.5(447,517)$ & 0.017 \\
\hline Hematocrit [\%] & $41.7(38.8,44.9)$ & $41.6(38.2,44.3)$ & $41.8(39.4,45.6)$ & 0.058 \\
\hline Platelet count $\left[\times 10^{3} / \mathrm{L}\right]$ & $212(182,255)$ & $197(169.5,228.5)$ & $232(198,284)$ & $<0.001$ \\
\hline Mean platelet volume [fL] & $9.5(8.9,10.2)$ & $9.8(9.2,10.4)$ & $9.3(8.7,9.8)$ & $<0.001$ \\
\hline \multicolumn{5}{|l|}{ Follow-up features: } \\
\hline Follow-up duration [day] & $336(309,360)$ & $336(309,366)$ & $333(300,360)$ & 0.197 \\
\hline MACE incidence & $81(16.5 \%)$ & $26(10.7 \%)$ & $55(22.4 \%)$ & $<0.001$ \\
\hline
\end{tabular}

All values are presented as mean \pm standard deviation, median (interquartile range), or number (percentage); ${ }^{a}$ WMR value is categorized according to its median, low-WMR $<755$ and high-WMR $\geq 755$; ${ }^{b}$ Multivessel disease was defined as coronary artery disease $\geq 2$ vessels. This parameter was available in 360 of patients; ACE-I — angiotensin-converting enzyme inhibitors; BP - blood pressure; CK-MB - creatine kinase MB isoenzyme; HDL - high density lipoprotein; LDL - low density lipoprotein; MACE — major adverse cardiovascular events; kinase MB isoenzyme; $\mathrm{HDL}$ - high density lipoprotein; $\mathrm{LDL}$ - low
$\mathrm{MI}$ - myocardial infarction; NYHA - New York Heart Association 
Table 2. Baseline characteristics and laboratories in groups according to major adverse cardiovascular events (MACE) incidence.

\begin{tabular}{|c|c|c|c|}
\hline & $\begin{array}{c}\text { MACE-positive } \\
(\mathbf{n}=\mathbf{8 1})\end{array}$ & $\begin{array}{l}\text { MACE-negative } \\
(n=409)\end{array}$ & $\mathbf{P}$ \\
\hline Age [years] & $60.6 \pm 13.1$ & $60.3 \pm 12.9$ & 0.875 \\
\hline Male & $49(60.5 \%)$ & $240(58.7 \%)$ & 0.762 \\
\hline Body mass index $\left[\mathrm{kg} / \mathrm{m}^{2}\right]$ & $28.3(25,30.8)$ & $27.7(24.6,30.7)$ & 0.602 \\
\hline Heart rate [bpm] & $80(75,86)$ & $80(75,85)$ & 0.753 \\
\hline Systolic BP [mm Hg] & $140(123,155)$ & $135(125,150)$ & 0.071 \\
\hline Diastolic BP [mm Hg] & $82(80,90)$ & $80(77,90)$ & 0.310 \\
\hline NYHA: & & & 0.479 \\
\hline Class 1 & $15(18.5 \%)$ & $107(26.2 \%)$ & \\
\hline Class 2 & $15(18.5 \%)$ & $59(14.4 \%)$ & \\
\hline Class 3 & $46(56.8 \%)$ & $219(53.5 \%)$ & \\
\hline Class 4 & $5(6.2 \%)$ & $24(5.9 \%)$ & \\
\hline Diabetes mellitus & $31(38.3 \%)$ & $114(27.9 \%)$ & 0.061 \\
\hline Hypertension & $54(66.7 \%)$ & $223(54.5 \%)$ & 0.044 \\
\hline Dyslipidemia & $13(16 \%)$ & $74(18.1 \%)$ & 0.660 \\
\hline Current smoking & $24(29.6 \%)$ & $105(25.7 \%)$ & 0.460 \\
\hline Familial history & $23(28.4 \%)$ & $119(29.1 \%)$ & 0.899 \\
\hline Diagnosis: & & & 0.254 \\
\hline Non-ST elevation MI & $8(11.8 \%)$ & $60(17.3 \%)$ & \\
\hline Unstable angina & $73(90.1 \%)$ & $349(82.7 \%)$ & \\
\hline Multivessel disease & $21(25.9 \%)$ & $103(25.2 \%)$ & 0.888 \\
\hline \multicolumn{4}{|l|}{ Drug histories: } \\
\hline Beta-blockers & $39(48.1 \%)$ & $187(45.7 \%)$ & 0.689 \\
\hline ACE-I & $17(21 \%)$ & $59(14.5 \%)$ & 0.144 \\
\hline Statins & $36(44.4 \%)$ & $173(42.3 \%)$ & 0.721 \\
\hline Nitrates & $35(43.2 \%)$ & $149(36.8 \%)$ & 0.277 \\
\hline Dual anti-platelet & $20(24.7 \%)$ & $92(22.5 \%)$ & 0.667 \\
\hline \multicolumn{4}{|l|}{ Biochemical markers: } \\
\hline CK-MB [IU/L] & $27(20,33)$ & $24(20,33)$ & 0.536 \\
\hline Troponin I [ng/ $\mu \mathrm{L}]$ & $0.01(0.01,0.3)$ & $0.01(0.01,0.2)$ & 0.814 \\
\hline $\mathrm{HDL}[\mathrm{mg} / \mathrm{dL}]$ & $38.5(33,44)$ & $38(33,44)$ & 0.792 \\
\hline LDL [mg/dL] & $86(71,105)$ & $86.5(68,96)$ & 0.491 \\
\hline Blood urea nitrogen [mg/dL] & $17.5(14,22)$ & $18.5(13.5,22.5)$ & 0.938 \\
\hline Creatinine [mg/dL] & $0.9(0.8,1.1)$ & $0.9(0.8,1.1)$ & 0.495 \\
\hline Blood sugar [mg/dL] & $119(94,171)$ & $106(93,134)$ & 0.051 \\
\hline White blood cell count $\left[\times 10^{3} / \mu \mathrm{L}\right]$ & $7.9(6.7,9.8)$ & $6.9(5.9,8.7)$ & 0.004 \\
\hline Neutrophil $\left[\times 10^{3} / \mu \mathrm{L}\right]$ & $4.6(3.9,6.9)$ & $4.2(3.4,5.5)$ & 0.021 \\
\hline Lymphocyte $\left[\times 10^{3} / \mu \mathrm{L}\right]$ & $2.2(1.6,2.7)$ & $2(1.5,2.5)$ & 0.308 \\
\hline Red blood cell count $\left[\times 10^{6} / \mu \mathrm{L}\right]$ & $470(441,504)$ & $474(440,507)$ & 0.663 \\
\hline Hematocrit [\%] & $41.4(38.2,44.4)$ & $41.8(38.9,44.9)$ & 0.105 \\
\hline Platelet count $\left[\times 10^{3} / \mathrm{L}\right]$ & $220(185,274)$ & $211(181,250)$ & 0.239 \\
\hline Mean platelet volume [fL] & $9.5(8.9,10)$ & $9.5(8.9,10.2)$ & 0.413 \\
\hline WMR & $863.2(687.5,1012.5)$ & $731.5(616.8,924.5)$ & 0.001 \\
\hline Follow-up duration [day] & $330(300,360)$ & $348(315,372)$ & 0.197 \\
\hline
\end{tabular}

All values are presented as mean \pm standard deviation, median (interquartile range), or number (percentage); abbreviations as in Table 1 


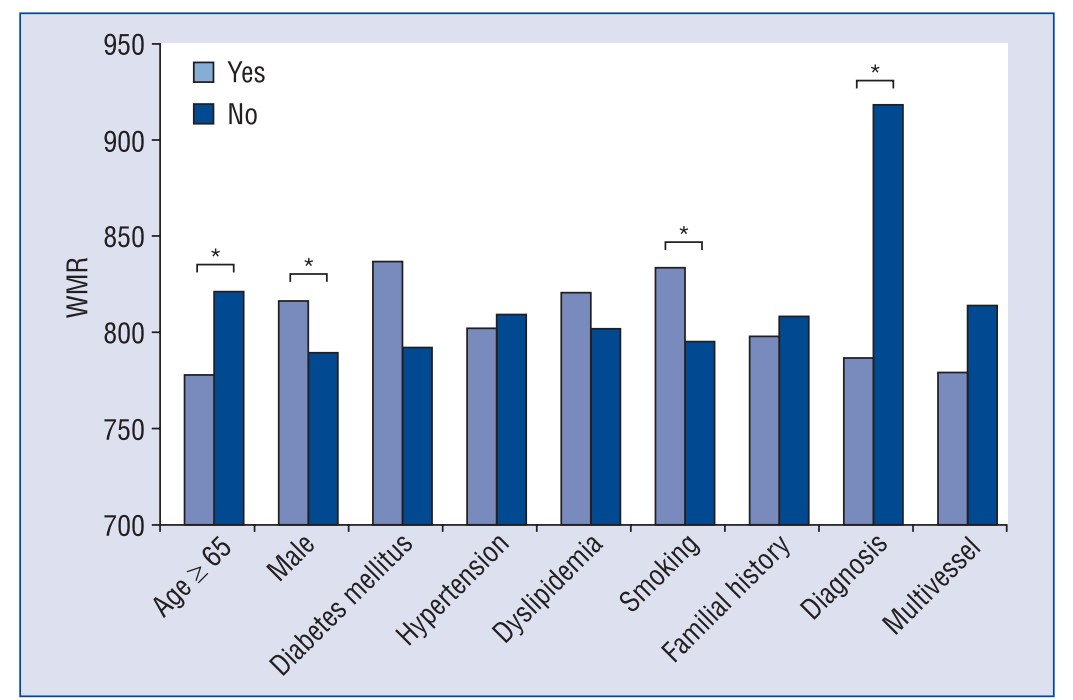

Figure 1. Comparison of white blood cell count to mean platelet volume ratio (WMR) values in the subgroups. Yes — being positive for mentioned variable; No - being negative for mentioned variable. Asterisk showing significant differences between paired groups.

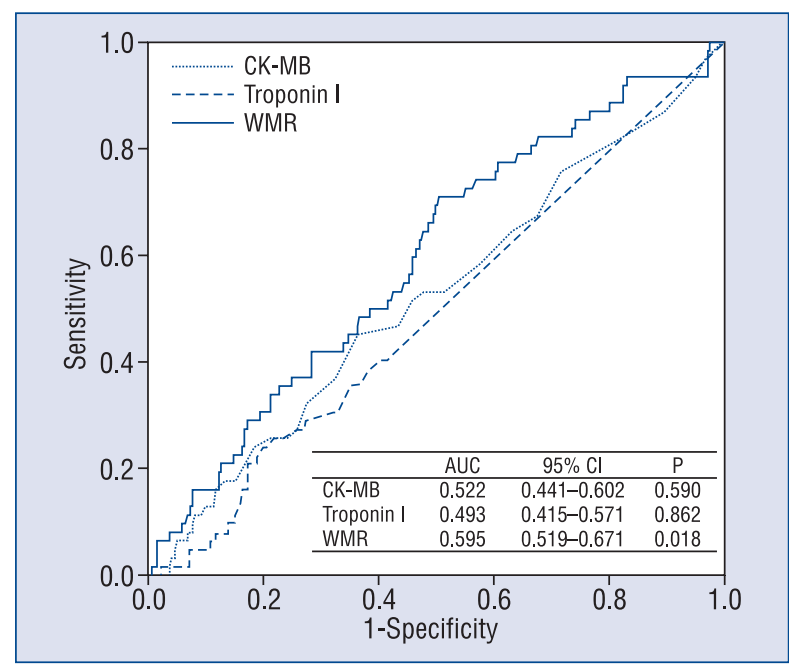

Figure 2. Receiver operating characteristics curve identifying the long-term clinical outcomes; AUC - area under curve; $\mathrm{Cl}$ - confidence interval; rest abbreviations as in Table 1.

variables with a p value of $<0.05$, including hypertension, WBC count, neutrophil count, and WMR, the elevated WMR was the strongest independent predictor of MACE, as well (HR 2.419, 95\% CI $1.515-3.862, \mathrm{p}<0.001$ ) (Table 3).

\section{Discussion}

In this prospective study, we showed, for the first time that the elevated baseline WMR was as-

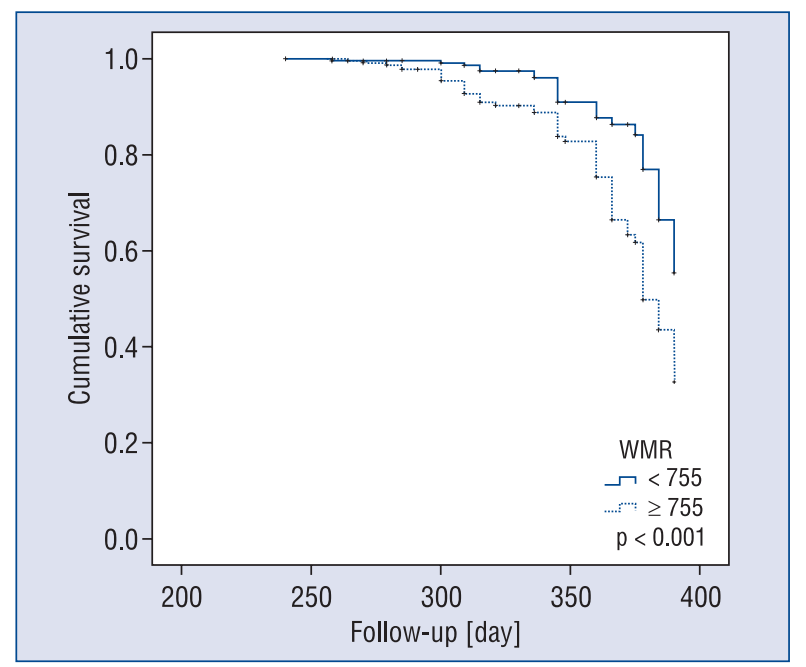

Figure 3. Kaplan-Meier curve showing difference between groups by white blood cell count to mean platelet volume ratio (WMR) for major adverse cardiovascular events (MACE)-free survival rate.

sociated with MACE incidence during long-term follow-up in the patients with NSTE-ACS. Being male and having hypertension were the independent predictors of MACE. Moreover, the high-WMR was associated with a significant increase in the risk of MACE incidence, and it was the strongest marker among complete blood count components predicting the long-term clinical outcomes.

Traditionally, it has been increasingly reported that atherosclerosis develops during the decades 
Table 3. Multivariate Cox regression analysis identifying the predictors of composite major adverse cardiovascular events (MACE).

\begin{tabular}{llcc}
\hline & HR & 95\% Cl & $\mathbf{P}^{\mathrm{a}}$ \\
\hline Unadjusted model: & & & 0.009 \\
Male & 2.689 & $1.277-5.662$ & 0.058 \\
Diabetes mellitus & 1.913 & $0.978-3.738$ & $<0.001$ \\
Hypertension & 3.780 & $1.860-7.681$ & 0.075 \\
Beta-blockers & 0.581 & $0.319-1.056$ & 0.029 \\
Nitrates & 1.954 & $1.073-3.558$ & 0.038 \\
CK-MB & 1.013 & $1.001-1.025$ & 0.002 \\
Blood urea nitrogen & 0.951 & $0.920-0.982$ & 0.210 \\
High density lipoprotein & 0.976 & $0.939-1.014$ & 0.014 \\
Platelet & 1.005 & $1.001-1.009$ & 0.012 \\
Hematocrit & 0.906 & $0.839-0.978$ & 0.055 \\
Mean platelet volume & 1.915 & $0.987-3.714$ & 0.008 \\
WMR & 2.406 & $1.257-4.607$ & 0.003 \\
Adjusted model: ${ }^{b}$ & & & $<001$ \\
Hypertension & 2.005 & $1.257-3.198$ & $1.515-3.862$ \\
WMR & 2.419 & & 0.003 \\
\hline
\end{tabular}

${ }^{a}$ All $p$ values of variables in the last step of backward stepwise regression model are listed; ${ }^{b} \mathrm{All}$ variables whose $\mathrm{p}$ values were $<0.05$ in the Table 2 were entered into the second model, adjusted Cox regression model; $\mathrm{Cl}$ - confidence interval; CK-MB - creatine kinase $\mathrm{MB}$ isoenzyme; HR — hazard ratio; WMR — white blood cell count to mean platelet volume ratio

of our life. The main factors involved in the development of NSTE-ACS include inflammation and thrombus formation resulting in the reduction of coronary artery flow and resultant ischemia [11]. During the rupture of an atherosclerotic plaque, platelets adhere to the injured endothelial cells and then are activated [4]. The activated ones release the inflammatory mediators, express some selectin molecules, and secrete cytokines and chemokines as well as proinflammatory lipids $[4,5,12]$. The adhesion molecules and mediators activate the leukocytes $[5,13]$ and promote the atherothrombotic events [5, 14].

Platelets are derived from megakaryocytes in the bone marrow, which have been increasingly shown to be involved in the hemostasis and maintenance of vascular endothelial integrity [12]. Although there are several laboratories to measure platelets' activity, none of them have been considered in daily clinical practice. The mean platelet volume, a platelet activation marker, is a widely available and easily measured hematologic test in a complete blood cell count test [7], and the elevated one has been demonstrated to be associated with diabetes mellitus, hypertension, hypercholesterolemia, and obesity [7]. In addition, it has been found to be a diagnostic and prognostic marker in patients with ACS or those undergoing percuta- neous coronary intervention [15-17]. However, in a prospective study, no relationship was found between increased baseline mean platelet volume and the clinical outcomes of patients undergoing elective angioplasty, but increases in postoperative serial measurements were associated with higher mortality rate instead [18]. This study failed to find any relationship between elevated baseline mean platelet volume and MACE incidence or MACE-free survival rate. We think that this may be caused by either our population's feature, which only included NSTE-ACS patients rather than high risk ones (i.e. STEMI) or its short follow-up duration, which might be associated with lower number of adverse events. The findings of this study and those of Shah et al. [18] underscore the need for further investigations regarding the relationship between mean platelet volume and the prognosis of ACS patients, especially NSTE-ACS cases.

In a longitudinal study, elevated total WBC count was associated with high rate mortality [19] and the increased risk of cardiovascular diseases [20]. Moreover, Sabatine et al. [10] reported that an elevated baseline WBC count correlated with impaired myocardial perfusion and increased 6 -month mortality in patients diagnosed with STEMI. In previous studies concerning the role of leukocytes in the prediction of ACS outcomes, 
it has been increasingly shown that those can be used as prognostic and risk stratification tools in such cases, although there have been controversies in terms of the best leukocyte subtype [8-10, 21]. In this study, we found that WBC count was associated with MACE-free survival rate at longterm follow-up, but it did not predict outcomes. These findings are consistent with previous studies showing the prognostic role of leukocyte differentials, including total WBC count, neutrophil count, lymphocyte, or neutrophil to lymphocyte ratio in patients with STEMI [22-25], NSTE-ACS [8], or NSTEMI [26]. Although the prognostic value of total WBC count has been reported in previous literatures, the superiority of WMR over WBC count was demonstrated in the present study by both the stronger probability of MACE-free survival rate and the multivariate analysis. We think that the ongoing studies concerning the relationship between complete blood count components and cardiovascular diseases might better clarify this notion and identify the best prognostic marker for implementation in clinical practice.

The interactions between platelets and leukocytes and vascular endothelial cells at culprit lesion have been found to be the main pathophysiologic mechanisms involved in the development of atherothrombotic events in the setting of ACS [4,6,12,27-29]. Platelet-leukocyte complexassessed by flow cytometry has been found as a pathophysiologic mechanism for the development of thrombogenesis [6], and monocyte-platelet aggregation was also shown as an early marker for acute MI [28] and NSTE-ASC patients [30]. Rinder et al. [5] showed that this cellular interaction is a dynamic process, in which platelet activation status and the ability of leukocytes to adhere result in different bindings. We should submit that although the elevated mean platelet volume is a marker of activated platelets, and its increase can contribute to decrease in the WMR values, if we consider that the both activated and inactivated platelets are involved in the platelet-leukocyte adhesion, WMR may not differ between patients with or without elevated baseline mean platelet volume.

\section{Limitations of the study}

The main limitation of the study was that we did not measure the markers of platelet-leukocyte interactions, including selectin molecules [31], adhesion ligands, and receptors [13, 32], which can be used as indicative of the platelet-leukocyte interactions. Thus, the evaluation of these biomarkers along with WMR may confirm causality. In addition, the small sample size of our study is another limitation; further large scale studies among STEMI patients and those undergoing angioplasty will be useful in order to prove these preliminary findings. Furthermore, we did not consider revascularization procedures developed during follow-up a MACE; hence, it may be associated with outcomes and provides further information with respect to any relationship between the WMR values of patients being revascularized and their outcomes. On the other hand, this shortcoming cannot be interfered with our findings showing the WMR as a prognosticator of long-term outcomes.

\section{Conclusions}

An elevated baseline WMR value was associated with clinical outcomes in patients with NSTE-ACS, and independently predicted the MACE incidence even stronger than other complete blood count components, including leukocyte differentials, platelet indices, and red blood cell indices.

\section{Conflict of interest: None declared}

\section{References}

1. Ross R. Atherosclerosis: An inflammatory disease. N Engl J Med, 1999; 340: 115-126.

2. Libby P. Mechanisms of acute coronary syndromes and their implications for therapy. N Engl J Med, 2013; 368: 2004$-2013$.

3. Margolis KL, Manson JE, Greenland P et al. Leukocyte count as a predictor of cardiovascular events and mortality in postmenopausal women: The Women's Health Initiative Observational Study. Arch Intern Med, 2005; 165: 500-508.

4. Davi G, Patrono C. Platelet activation and atherothrombosis. N Engl J Med, 2007; 357: 2482-2494.

5. Rinder HM, Bonan JL, Rinder CS, Ault KA, Smith BR. Activated and unactivated platelet adhesion to monocytes and neutrophils. Blood, 1991; 78: 1760-1709.

6. Botto N, Sbrana S, Trianni G et al. An increased platelet-leukocytes interaction at the culprit site of coronary artery occlusion in acute myocardial infarction: A pathogenic role for "no-reflow" phenomenon? Int J Cardiol, 2007; 117: 123-130.

7. Chu SG, Becker RC, Berger PB et al. Mean platelet volume as a predictor of cardiovascular risk: A systematic review and metaanalysis, J Thromb Haemost, 2010; 8: 148-156.

8. Dehghani MR, Rezaei Y, Taghipour-Sani L. Superiority of total white blood cell count over other leukocyte differentials for predicting long-term outcomes in patients with non-ST elevation acute coronary syndrome. Biomarkers, 2014; 19: 378-384.

9. Horne BD, Anderson JL, John JM et al. Which white blood cell subtypes predict increased cardiovascular risk? J Am Coll Cardiol, 2005; 45: 1638-1643.

10. Sabatine MS, Morrow DA, Cannon CP et al. Relationship between baseline white blood cell count and degree of coronary artery disease and mortality in patients with acute coronary 
syndromes: A TACTICS-TIMI 18 (Treat Angina with Aggrastat and determine Cost of Therapy with an Invasive or Conservative Strategy-Thrombolysis in Myocardial Infarction 18 trial) substudy. J Am Coll Cardiol, 2002; 40: 1761-1768.

11. Braunwald E. Unstable angina and non-ST elevation myocardial infarction. Am J Respir Crit Care Med, 2012; 185: 924-932.

12. Kaplan ZS, Jackson SP. The role of platelets in atherothrombosis. Hematology Am Soc Hematol Educ Program, 2011; 2011: 51-61.

13. Rinder C, Fitch J. Amplification of the inflammatory response: Adhesion molecules associated with platelet/white cell responses. J Cardiovasc Pharmacol, 1996; 27 (suppl. 1): S6-S12.

14. Freedman JE, Loscalzo J. Platelet-monocyte aggregates: Bridging thrombosis and inflammation. Circulation, 2002; 105: 2130-2132 .

15. Goncalves SC, Labinaz M, Le May M et al. Usefulness of mean platelet volume as a biomarker for long-term outcomes after percutaneous coronary intervention. Am J Cardiol, 2011; 107: 204-209.

16. Martin JF, Bath PM, Burr ML. Influence of platelet size on outcome after myocardial infarction. Lancet, 1991; 338: 1409-1411.

17. Seyyed-Mohammadzad MH, Eskandari R, Rezaei Y et al. Prognostic value of mean platelet volume in patients undergoing elective percutaneous coronary intervention. Anadolu Kardiyol Derg, 2015; 15: 25-30.

18. Shah B, Oberweis B, Tummala L et al. Mean platelet volume and long-term mortality in patients undergoing percutaneous coronary intervention. Am J Cardiol, 2013; 111: 185-189.

19. Ruggiero C, Metter EJ, Cherubini A, Maggio M, Sen R, Najjar SS et al. White blood cell count and mortality in the Baltimore Longitudinal Study of Aging. J Am Coll Cardiol, 2007; 49: 1841-1850.

20. Kannel WB, Anderson K, Wilson PW. White blood cell count and cardiovascular disease. Insights from the Framingham Study. JAMA, 1992; 267: 1253-1256.

21. 21. Huang G, Zhong XN, Zhong B et al. Significance of white blood cell count and its subtypes in patients with acute coronary syndrome. Eur J Clin Invest, 2009; 39: 348-358.

22. Cannon CP, McCabe CH, Wilcox RG, Bentley JH, Braunwald E. Association of white blood cell count with increased mortality in acute myocardial infarction and unstable angina pectoris. OPUSTIMI 16 Investigators. Am J Cardiol, 2001; 87: 636-639.

23. Chia S, Nagurney JT, Brown DF et al. Association of leukocyte and neutrophil counts with infarct size, left ventricular function and outcomes after percutaneous coronary intervention for ST-elevation myocardial infarction. Am J Cardiol, 2009; 103: 333-337.

24. Mariani M, Fetiveau R, Rossetti E et al. Significance of total and differential leucocyte count in patients with acute myocardial infarction treated with primary coronary angioplasty. Eur Heart J, 2006; 27: 2511-2515.

25. Núñez J, Núñez E, Bodí $V$ et al. Usefulness of the neutrophil to lymphocyte ratio in predicting long-term mortality in ST segment elevation myocardial infarction. J Am Coll Cardiol, 2008; 101: 747-752.

26. Azab B, Zaher M, Weiserbs KF et al. Usefulness of neutrophil to lymphocyte ratio in predicting short- and long-term mortality after nonST-elevation myocardial infarction. Am J Cardiol, 2010; 106: 470-476.

27. Brambilla M, Camera M, Colnago D et al. Tissue factor in patients with acute coronary syndromes: Expression in platelets, leukocytes, and platelet-leukocyte aggregates. Arterioscler Thromb Vasc Biol, 2008; 28: 947-953.

28. Furman MI, Barnard MR, Krueger LA et al. Circulating monocyte-platelet aggregates are an early marker of acute myocardial infarction. J Am Coll Cardiol, 2001; 38: 1002-1006.

29. Mickelson JK, Lakkis NM, Villarreal-Levy G, Hughes BJ, Smith CW. Leukocyte activation with platelet adhesion after coronary angioplasty: A mechanism for recurrent disease? J Am Coll Cardiol, 1996; 28: 345-353.

30. Zhang SZ, Jin YP, Qin GM, Wang JH. Association of plateletmonocyte aggregates with platelet activation, systemic inflammation, and myocardial injury in patients with non-st elevation acute coronary syndromes. Clin Cardiol, 2007; 30: 26-31.

31. Palabrica T, Lobb R, Furie BC et al. Leukocyte accumulation promoting fibrin deposition is mediated in vivo by P-selectin on adherent platelets. Nature, 1992; 359: 848-851.

32. Rinder HM, Bonan JL, Rinder CS, Ault KA, Smith BR. Dynamics of leukocyte-platelet adhesion in whole blood. Blood, 1991; 78: 1730-1737. 